\title{
Microbial community characteristics during simultaneous nitrification-denitrification process: effect of $\mathrm{COD} / \mathrm{TP}$ ratio
}

\author{
Jian Zhang ${ }^{1}$, Wenlin $\mathrm{Jia}^{2}$, Rong Wang ${ }^{1}$, Huu Hao $\mathrm{Ngo}^{3}$, Wenshan $\mathrm{Guo}^{3}$, Huijun $\mathrm{Xie}^{4}$, Shuang \\ Liang $^{1}$ \\ ${ }^{1}$ Shandong Provincial Key Laboratory ofWater Pollution Control and Resource Reuse, School of \\ Environmental Science and Engineering, Shandong University, Jinan 250100, China \\ ${ }^{2}$ School of Chemistry and Chemical Engineering, Jiangsu Normal University, Xuzhou 221116, China \\ ${ }^{3}$ School of Civil and Environmental Engineering, University of Technology Sydney, Broadway NSW \\ 2007, Australia \\ ${ }^{4}$ Environmental Research Institute, Shandong University, Jinan 250100, China
}

\begin{abstract}
To evaluate the impact of chemical oxygen demand (COD)/total phosphorus (TP) ratio on microbial community characteristics during low-oxygen simultaneous nitrification and denitrification process, three anaerobic-aeration (low-oxygen) sequencing batch reactors, namely R1, R2, and R3, were performed under three different COD/TP ratios of 91.6, 40.8, and 27.6. The community structures of each reactor were analyzed via molecular biological technique. The results showed that the composition of ammonia-oxidizing bacteria (AOB) was affected, indicated by Shannon indexes of the samples from R1, R2, and R3.Nitrosomonas was identified to be the dominant AOB in all SBRs. Moreover, the copy numbers of nitrifiers were more than those of denitrifiers, and the phosphorus-accumulating organisms to glycogen-accumulating organisms ratio increased with the decrease of COD/TP ratio.
\end{abstract}

\section{Keywords}

Microbial community COD/TP ratio Simultaneous nitrification and denitrification Molecular biological technique

\section{Introduction}

Nutrient (mainly nitrogen and phosphorus) enrichment is acknowledged to be the main cause of eutrophication and is becoming one of the most serious environmental and ecological 
concerns worldwide (Dupas et al. 2015). Nitrogen and phosphorus are now required to be more effectively removed during wastewater treatment, which leads to a great need of more efficient biological nutrient removal processes. Thus, simultaneous nitrification and denitrification (SND) process, which has higher nitrogen removal efficiency and low energy consumption, has recently attracted increasing attention for nutrient removal (Holman and Wareham 2005, Castro Daniel et al. 2009, Fu et al. 2009).

In traditional biological treatment processes, nitrogen removal is mainly achieved by separate anaerobic and aerobic phases and is generally carried out in separate bioreactors or by different aeration intervals. However, as it has been reported that some heterotrophic nitrifiers could denitrify nitrite and nitrate aerobically; nitrification and denitrification occurring concurrently in a single reactor under aerobic conditions is often referred as SND process (Chiu et al. 2007). Generally, SND occurs naturally inside microbial biofilms and flocs due to the oxygen gradient established across the biomass (Meyer et al. 2005). Moreover, some heterotrophic bacteria, e.g., Alcaligenes faecalis and Thiosphaera pantotropha, are capable of performing SND by using organic substrates aerobically as sources of carbon and energy to convert ammonium aerobically into nitrogen gas (Chiu et al. 2007). Meanwhile, Nitrosomonas-like ammonia-oxidizing bacteria (AOB) was widely reported to be capable of denitrification (Shrestha et al. 2002). The operating parameters of SND processes, such as oxygen concentration (Hocaoglu et al. 2011), temperature (Zhang et al. 2009), and $\mathrm{C} / \mathrm{N}$ ratio (Chiu et al. 2007), were found to significantly affect microbial metabolisms, and consequently nutrient removal performance. $\mathrm{C} / \mathrm{P}$ ratio is reported to significantly influence the nutrients removal and is an essential factor for the optimization of wastewater treatment process, such as anaerobic-anoxic/nitrification sequencing batch reactor ( $\mathrm{A}_{2} \mathrm{~N}-\mathrm{SBR}$ ) (Wang et al. 2009), UniFed SBR process (Zhao et al. 2008), and SND process (Ge et al. 2010, Jia et al. 2013a). However, to date, special attempts have not yet been devoted to investigating the impact of chemical oxygen demand (COD)/ total phosphorus (TP) ratio on the performance of SND processes in terms of microbial community characteristics.

Additionally, in SND processes, denitrification is driven mainly by intracellular carbon source poly- $\beta$-hydroxyalkanoates (PHA), which is produced by phosphorusaccumulating organisms such as phosphate-accumulating organisms (PAOs) during biological phosphorus removal (Zeng et al. 2003, Wang et al. 2011). Under anaerobic conditions, PAOs are able to take up organic substrates and store them as PHA using the 
energy obtained from glycogen utilization and hydrolysis of the intracellular stored polyphosphate. Under aerobic or anoxic conditions, PHA was oxidized for phosphorus uptake and denitrification. Hence, it is reasonably hypothesized that the COD/TP ratio, especially the phosphorus load, could influence the enrichment of PAOs as well as the synthesis of PHA, leading to the change of denitrification rate and SND efficiency.

Furthermore, it was reported that the fractions of nitrogen and phosphorus, removed by different biological pathways, strongly depended on $\mathrm{C}: \mathrm{N}: \mathrm{P}$ ratio of the influent (Wang et al. 2009). In particular, the ratio of COD/TP has been shown to significantly affect the microbial community structure and the distribution of PAOs and glycogen-accumulating organisms (GAOs), which were two dominating heterotrophic microbes during biological nutrient removal (Chuang et al. 2011). Many studies have shown that a low COD/TP ratio was favorable to the growth of PAOs instead of GAOs in the enhanced biological phosphorus removal processes (EBPR) (Mino et al. 1998, Thomas et al. 2003). However, in SND process, the microbial community was more complex than that in the EBPR process. A detailed analysis of microbial community characteristics would, therefore, provide valuable information to the better understanding of nutrient removal mechanisms in SND processes under different $\mathrm{COD} / \mathrm{TP}$ ratios.

The effect of COD/TP ratio on SND performance (i.e., nutrients removal efficiency) has been reported in our previous work (Jia et al. 2013a). As a more fundamental follow-up work, the main effort herein was focused on the microbial community characteristics in order to better understand the underlying mechanisms regarding the impact of COD/TP ratio on SND performance. The community structures of total bacteria (based on 16S rRNA), nitrifiers (AOB based on ammonia monooxygenase submit A gene (amoA)), and denitrifiers (based on nitrous oxide reductase gene (nos $Z$ )) were analyzed by polymerase chain reaction (PCR)-denaturing gradient gel electrophoresis (DGGE) technique and real-time quantitative PCR (qPCR) detecting system. Besides, the PAOs/GAOs ratio was investigated by fluorescent in situ hybridization (FISH).

\section{Materials and methods}

SBR setup and operation

Experiments were performed in three identical lab-scale anaerobic-aeration SBRs (namely R1, R2, and R3), which were operated in parallel under different COD/TP ratios. Each SBR has an effective volume of $5 \mathrm{~L}$. One operating cycle consisted of four stages in series, i.e., 
anaerobic stage (90 $\mathrm{min})$, aeration stage (180 $\mathrm{min})$, settling stage (70 $\mathrm{min})$, and decant stage (20 min). Synthetic wastewater with same COD and ammonium but different TP concentrations were fed into three SBRs, corresponding to the average influent COD/TP ratios of 91.6, 40.8, and 27.6 for R1, R2, and R3, respectively, and theoretical COD/TN ratio of 10.0 for all three reactors. The schematic diagram of the SBR system and detailed composition of synthetic wastewater can be found in our previous work (Jia et al. 2013a).

All SBRs were seeded with the sludge collected from a parent SND SBR, which has been running for more than 1 year in Shandong provincial key Laboratory of water pollution control and resource reuse. The water temperature was maintained at $25 \pm 2{ }^{\circ} \mathrm{C}$ over the entire experimental period. The solids retention time (SRT) was kept at 20 days for all three reactors to eliminate the influence of operation parameter on biomass diversities, and the mixed liquor suspended solid (MLSS) concentration was approximately in the range of 3,000-3,500 mg/L. An on/off control system was used to control air supply during aeration stage to keep the dissolved oxygen (DO) level between 0.35 and $0.80 \mathrm{mg} / \mathrm{L}$. The DO profiles of three SBRs were shown in Fig. S1 supplementary data.

After running under the selected COD/TP ratios for over 3 months, all SBRs reached their steady state. The concentrations of the effluent were then measured to investigate the nutrient removal efficiency.

\section{DNA extraction and PCR-DGGE}

Once the SBRs reached steady state, the sludge samples of each reactor were collected and centrifuged for DNA extraction. The total genomic DNA was extracted from sludge sample using PowerSoil ${ }^{\mathrm{TM}}$ DNA Isolation Kit (MO-BIO Laboratories, USA). In order to investigate the total bacteria, nitrifiers and denitrifiers community composition in three SBRs, the bacterial 16S rRNA gene and functional genes amoA and nosZwere amplified using primer sets $338 \mathrm{~F} / 518 \mathrm{R}$, amoA-1 F/amoA-2R, and nosZ-F/nosZ-1622R, respectively (Ibekwe et al. 2003, Enwall et al. 2005, Zhang et al. 2011). A 40-nucleotide GC-clamp was added on the $5^{\prime}$ end of the forward primers to improve the detection of sequence variations in amplified DNA fragments by subsequent DGGE.

For functional genes amplification, PCR reactions were carried out according to the protocol described previously (Hu et al.2011). The PCR protocol for 16S rRNA amplification was set as follows: $95^{\circ} \mathrm{C}$ for $5 \mathrm{~min}, 16$ cycles of $94{ }^{\circ} \mathrm{C}$ for $30 \mathrm{~s}, 65^{\circ} \mathrm{C}$ for $30 \mathrm{~s}$, and $72{ }^{\circ} \mathrm{C}$ for $45 \mathrm{~s}$, with $0.5^{\circ} \mathrm{C}$ decrease of the annealing temperature every cycle, followed 
by 19 cycles of $94{ }^{\circ} \mathrm{C}$ for $30 \mathrm{~s}, 57^{\circ} \mathrm{C}$ for $30 \mathrm{~s}$, and $72{ }^{\circ} \mathrm{C}$ for $45 \mathrm{~s}$, and a final extension cycle at $72{ }^{\circ} \mathrm{C}$ for $7 \mathrm{~min}$.

$D G G E$, cloning, sequencing, and phylogenetic analysis

DGGE analysis was conducted using the Bio-Rad Dcode system (Bio-Rad, USA). Electrophoresis was performed at $120 \mathrm{~V}$ for $7.5 \mathrm{~h}$ in $1 \times$ TAE buffer at a constant temperature of $60^{\circ} \mathrm{C}$. The liner gradients were optimized for efficient separation of bands and were shown as follows: $25-40 \%$ for $a m o A, 30-50 \%$ for $n o s Z g e n e$ and $38-52 \%$ for $16 \mathrm{~S}$ rRNA. To visualize bands, DGGE gels were stained by ethidium bromide and photographed under UV-light after electrophoresis. The species diversity was measured by Shannon-Wienerindex $\left(H^{\prime}\right)$, which was calculated by the following equation:

$$
H^{\prime}=\sum_{i=1}^{s} p_{i} \log _{e} p_{i}
$$

where $p_{i}$ represents the intensity proportion of band $i$ in the DGGE profile and $s$ is the total number of bands.

Specific bands were excised, washed, and dissolved in sterile water. Then the product was used as template and re-amplified with appropriate primes. The PCR protocol for reamplification was the same as above described except with free GC-clamp former primers. Following the manufacturer's protocol, the PCR amplicons were purified using the E.Z.N.A ${ }^{\circledR}$ Gel Extraction Kit (OMEGA), and then ligated into the pMD19-T Vector (TaKaRa, Japan) and were further transformed into competent cells DH5 $\alpha$ (TaKaRa). White colonies were picked from each cloned sample and cultivated overnight for sequencing (Sangon Biotech., China). The obtained sequences were compared with the other available sequences in the GenBank by BLAST search. Phylogenetic trees were conducted by using MEGA 5, the neighbor-joining method with a bootstrap of 1,000 replications.

\section{Quantitative PCR}

Nitrifiers, denitrifiers, and total bacteria genes were quantified by Roche LightCycler ${ }^{\circledR} 480$ on SYBR Green I method. All the samples were investigated with primer sets and protocols as the normal PCR. Reaction mixtures contained $1 \mu \mathrm{L}$ of template DNA, $10 \mu \mathrm{L}$ of SYBR $\mathbb{R}$ Premix Ex Taq ${ }^{\mathrm{TM}}$ (TaKaRa), $0.4 \mu \mathrm{M}$ primer (without GC-clamp), and of $7 \mu \mathrm{L} \mathrm{ddH}_{2} \mathrm{O}$. Standard curves for qPCR assays were developed using the plasmids extracted from the pure cultures of correct insert clones of each target gene. The amplification was monitored and 
analyzed by the $C_{t}$ value. Each PCR was performed three times. The specificity of PCR for each target gene was checked using melting curve analysis.

FISH

Sludge sampled from each SBR was firstly fixed in $4 \%$ paraformaldehyde and incubated for $180 \mathrm{~min}$ at $4{ }^{\circ} \mathrm{C}$. After fixation, samples were centrifuged for $5 \mathrm{~min}$ at $12,000 \mathrm{rpm}$, then washed twice in $1 \times$ phosphate buffer saline (PBS), and re-suspended in volume of 1:1 ethanol/PBS buffer for storage at $-20{ }^{\circ} \mathrm{C}$. The fixed samples were dried overnight on a hybridization slide and then incubated in 50, 80, and $100 \%$ ethanol for 3 min per each solution. After dehydration, the tagged hybridization buffer $(10 \mu \mathrm{L})$ and $25 \mathrm{ng}$ of tagged probe mixture were added to each sample and incubated for $3 \mathrm{~h}$ in a humid chamber at $46{ }^{\circ} \mathrm{C}$. The probe mixtures for total bacteria (EubMix) contained equal EUB338, EUB338-II, and EUB338-III. The probe mixtures for PAOs (PAOMix) and GAOs (GAOMix) contained equal PAO462, PAO846 and equal GAOQ431, GAOQ989, respectively. After hybridization, the microscope slides were immersed into $50 \mathrm{~mL}$ of tagged washing solution consisting of $1 \mathrm{M}$ Tris ( $\mathrm{pH} 8), 10 \% \mathrm{SDS}(\mathrm{w} / \mathrm{v})$, and $5 \mathrm{M} \mathrm{NaCl}$ for $15 \mathrm{~min}$ at $48{ }^{\circ} \mathrm{C}$. The samples were observed with an epifluorescence microscope, and the PAOs/GAOs ratio was estimated using ImagePro Plus 6.0. The probes and experimental parameters are described in Table S1 in supplementary data.

\section{Results and discussion}

Effect of COD/TP ratio on microbial community structure

After running for over 3 months, the pollution removal efficiency and SND efficiency in each reactor were shown in Table S2. In all three SBRs, the SND efficiency was above $80 \%$, regardless of $\mathrm{COD} / \mathrm{TP}$ ratio, indicating the occurrence of SND process. Both $\mathrm{TP}$ and $\mathrm{TN}$ removal efficiencies were enhanced along with the decrease of COD/TP ratio, and R3 gained relatively high nitrogen and phosphorus removal efficiency under low COD/TP ratio. It was mainly achieved by some PAOs capable of denitrification, i.e., denitrifying PAOs (DPAOs), using PHA stored in the anaerobic stage as carbon source and nitrite/nitrate as electron acceptors (Jia et al. 2013a).

In order to get an in-depth understanding regarding the impact of $\mathrm{COD} / \mathrm{TP}$ ratio on SND performance, the microbial community characteristics were determined by molecular biological technique. The community structure of total bacteria was investigated by PCR- 
DGGE and the DGGE patterns based on 16S rRNA gene are shown in Fig. 1a. It can be seen that the DGGE patterns of three sludge samples from SBRs under different COD/TP ratios were similar with no considerable differences. The similarities of different lanes of total bacteria analyses were also calculated based on the DGGE patterns and a dendrogram was constructed using the UPGMA method (Fig. 1b). For calculation of the Shannon diversity index, each band was considered as a unique species. The calculated Shannon-Wiener indexes of total bacteria in $\mathrm{R} 1, \mathrm{R} 2$, and $\mathrm{R} 3$ were $3.05,3.02$, and 2.86 , respectively.

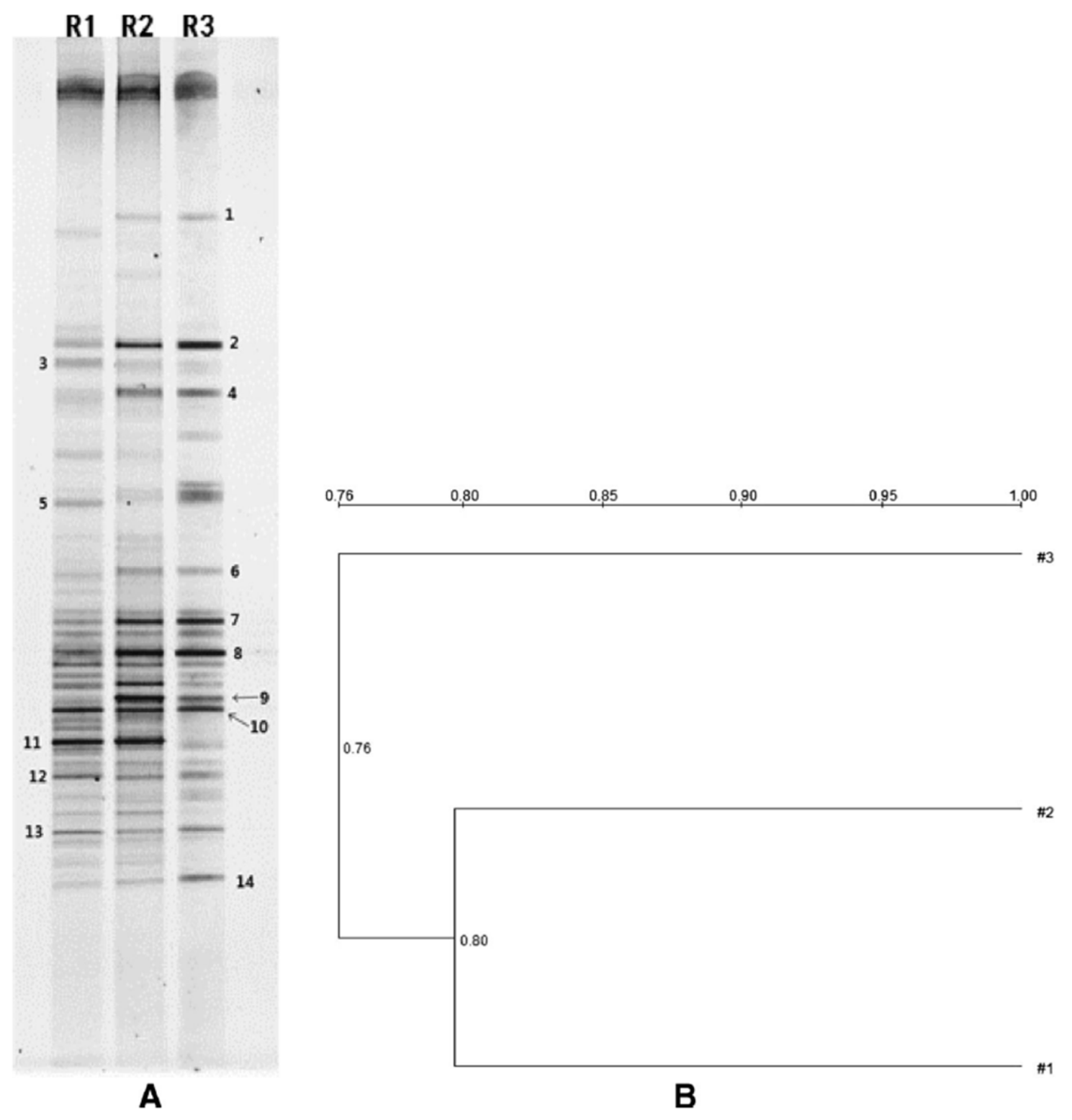

Fig. 1 a DGGE profiles of total bacteria and $\mathbf{b}$ cluster analysis of sludge samples from SBRs under different $\mathrm{COD} / \mathrm{TP}$ ratios 


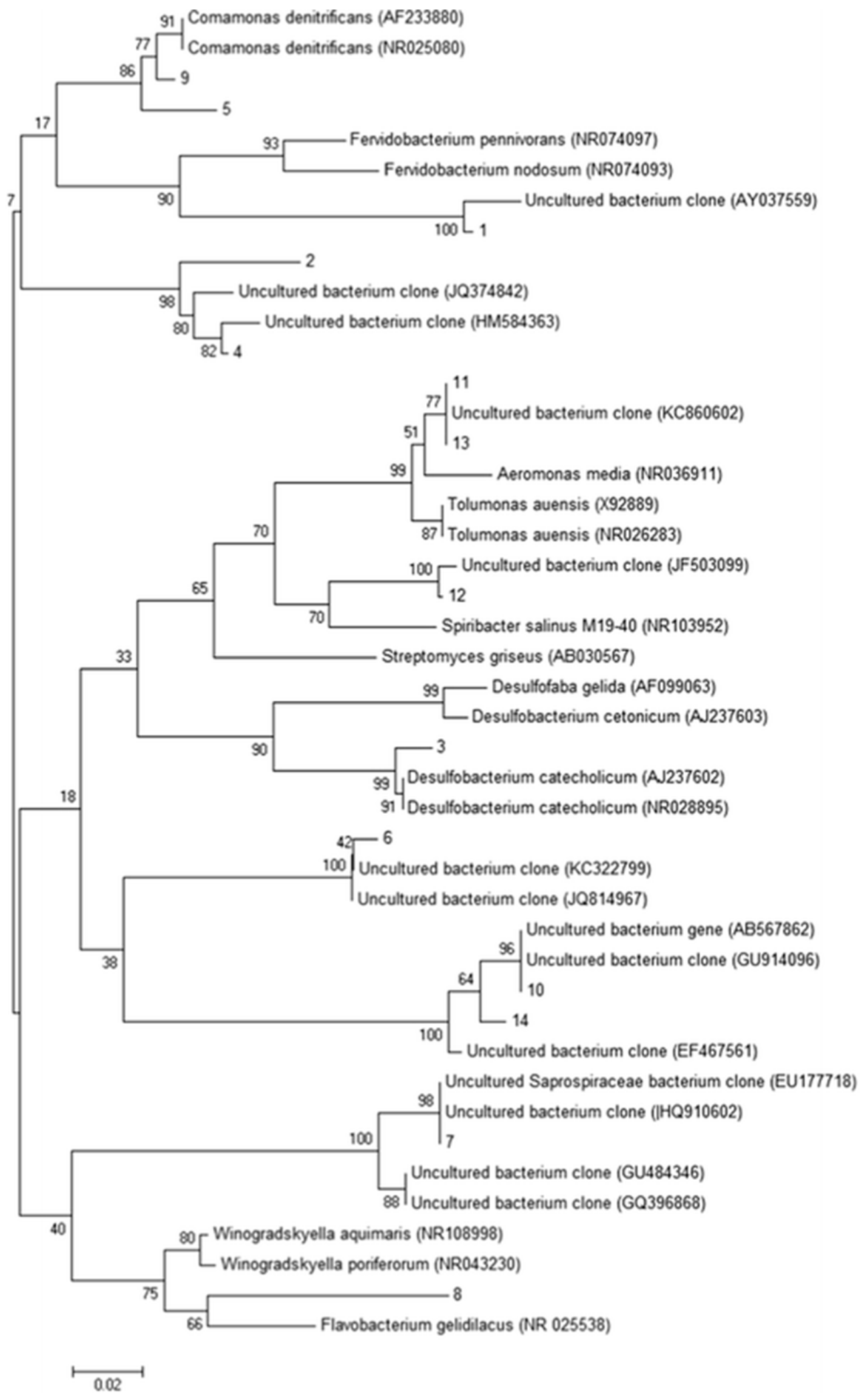

Fig. 2 Neighbor-joining phylogenetic tree of total bacteria in SBRs under different COD/TP ratio, based on partial sequences of $16 \mathrm{~s}$ rRNA V3 part. Sequence types correspond with the sequence types presented in Fig. 2a 
Some typical sequences were successfully read from the DGGE gels and the NJ phylogenetic tree of total bacteria based on $16 \mathrm{~s}$ rRNA gene sequences was constructed (Fig. 2). It was elucidated that bands 12 and 13, which were most identical to Tolumonas founded in a freshwater lake, were observed in all samples with similar intensity (Fischer-Romero et al. 1996). Sequence identical to Desulfobulbaceae (band 3) was only observed in R1. Sequence identical to Flavobacterium founded in lakes was observed intensely in R2 and R3 (van Trappen et al. 2003). The results showed that the whole biomass consisted of $\beta, \gamma, \delta$-Proteobacteria, Flavobacteria, and Thermotogales. With the increase of the COD/TP ratio, the population of $\gamma$-Proteobacteria exhibited a slightly decreasing trend, while Flavobacteria and Thermotogales seemed to increase. However, in general, no significant differences caused by the change of COD/TP ratio were found in three SBRs.

\section{Effect of COD/TP ratio on nitrifiers and denitrifiers}

The DGGE patterns based on amoA gene are demonstrated in Fig. 3a. The composition of AOB community was slightly affected by COD/TP ratio. The Shannon-Wiener indexes of three sludge samples from R1, R2, and R3 turned out to be 1.99, 1.35, and 1.51, respectively. The diversity of AOB in R1 was higher than those in R2 and R3. Sequence amoA1 and amoA2 dominated in all samples, whereas other bands were comparatively weak (Fig. 3a).

The NJ phylogenetic tree of AOB based on amoA gene (Fig. 3b) illustrated that the dominant amoA sequences (especially amoA1 and amoA2, which were found in all samples and quite bright) were very similar to the sequences reported in other studies and affiliated to a Nitrosomonas-like cluster found in several wastewater treatment plants (WWTPs) and a full-scale submerged membrane bioreactor (Yu et al. 2011, Gao et al. 2013). This suggested that Nitrosomonas was the dominant AOB in all SBRs. The capacity of both nitrification and denitrification under low oxygen conditions lead the accumulation of Nitrosomonas in SND process (Shrestha et al. 2002). Meanwhile, some unique bands (amoA4 and amoA6) were found in certain SBRs, which were caused by the different COD/TP ratios. Some sequences similar to amoA4 were also discovered in other SND processes (Jia et al. 2013b). However,Nitrosospira-like sequences, which was found to be dominated in AOB community in some study (Liu et al.2010), were only found in R3 under the investigated conditions. It seems that the increase of influent phosphorus load could promote the competition of Nitrosospira during SND process. 

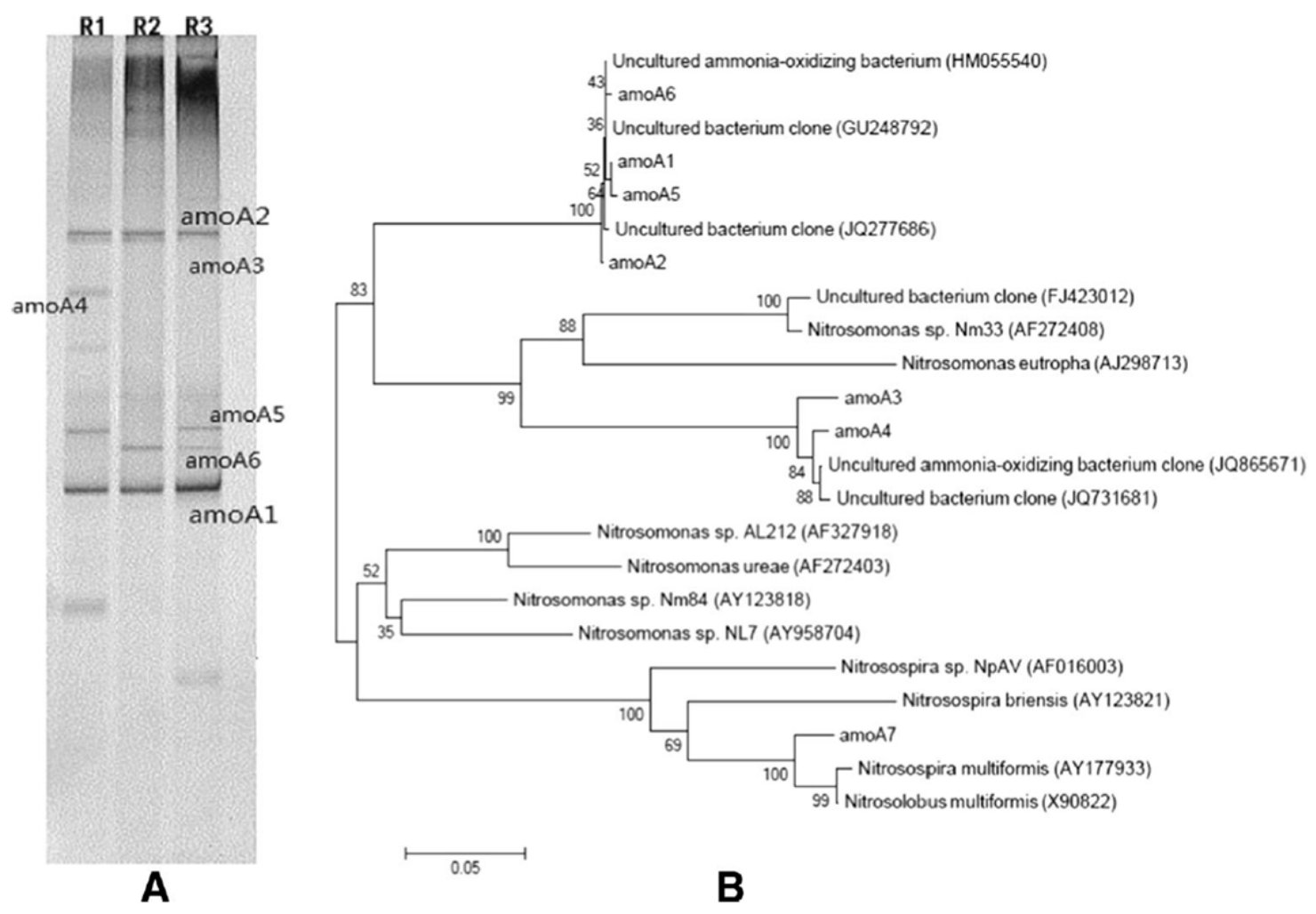

Fig. 3 a AOB patterns based on $a m o A$ gene and $\mathbf{b}$ Neighbor-joining phylogenetic tree of AOB based on partial sequences of $a m o A$ of three SBRs under different COD/TP ratio

In contrast, no significant difference was found in the composition of denitrifier community among the SBRs, according to the DGGE patterns of functional gene nosZ (Fig. 4a). It seems that all the denitrifiers, under the investigated conditions, could very well cope with the change of COD/TP ratio. The phylogenetic tree of denitrifiers based on $\operatorname{nos} Z$ gene showed that all the sequences divided into two parts with high similarity within each part (Fig. 4b). The two parts exhibited high similarities with the uncultured bacterium clones ofnos $Z$ gene previously found in an intermittently aerated partial nitritation SBR and a highly managed turf grass systems, respectively (Dell et al. 2010, Gabarro et al. 2013). Nevertheless, all sequences showed a low similarity with the known denitrifying bacteria, indicating these sequences may represent new species. 


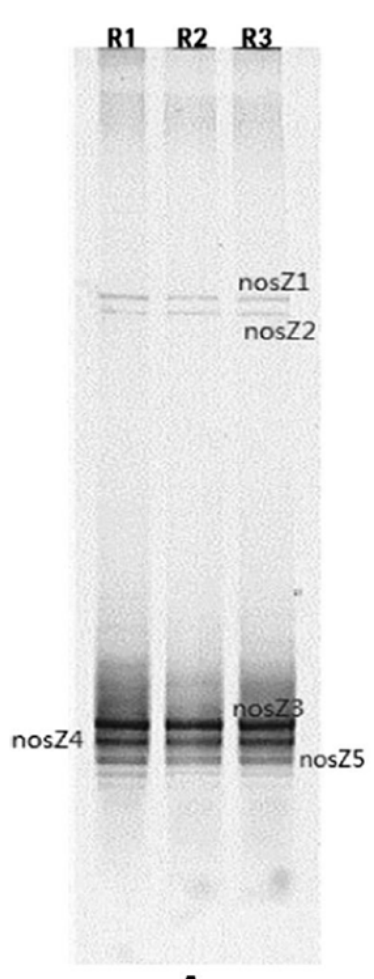

A

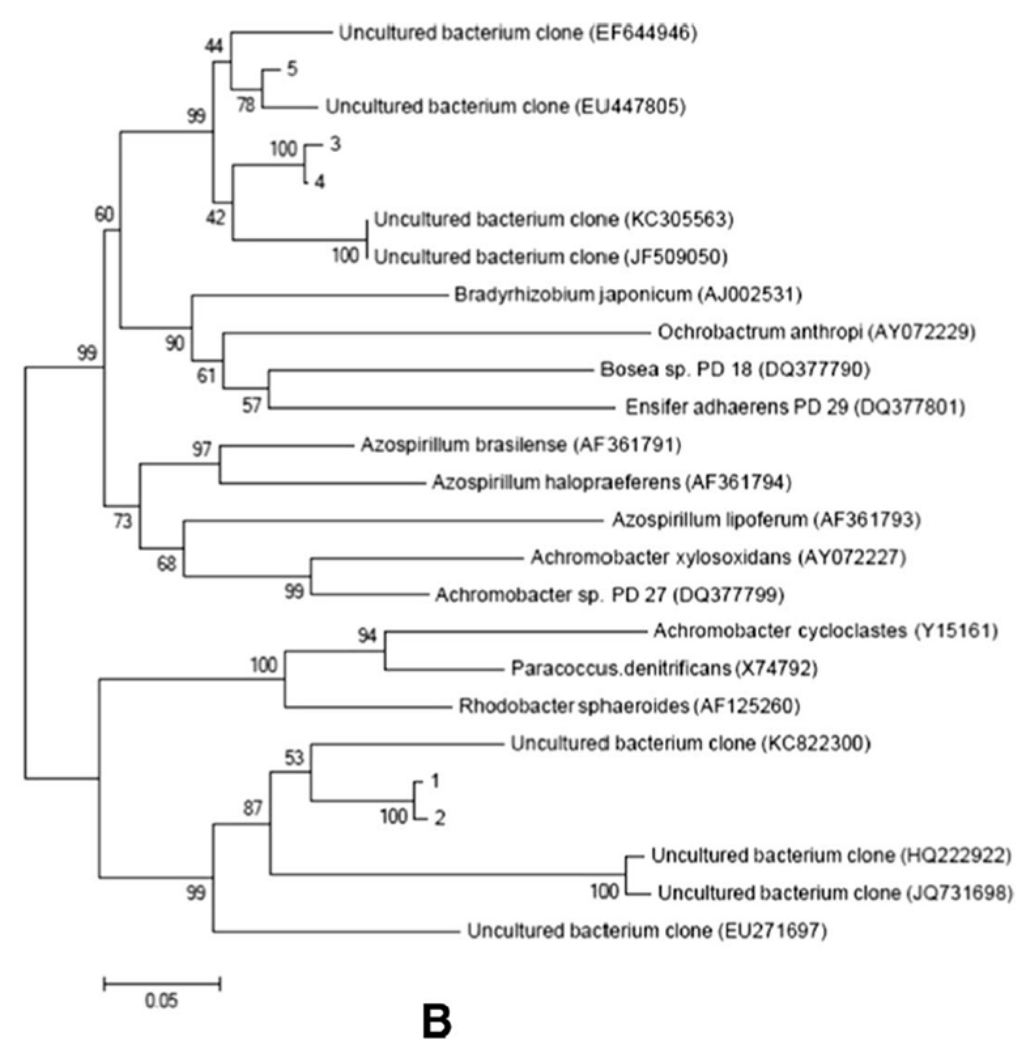

Fig. 4 a Denitrifier patterns based on nos $Z$ gene and $\mathbf{b}$ Neighbor-joining phylogenetic tree of denitrifier based on partial sequences of nos $Z$ of three SBRs under different COD/TP ratio

Unlike PCR-DGGE results, the results of real-time qPCR showed very minor difference in the quantity of AOB community (Fig. 5). The ratios of amoA/bacterial $16 \mathrm{~S}$ rRNA gene were almost identical (except from $8.5 \times 10^{-5}$ to $9.2 \times 10^{-5}$ on average), which were consistent with another study (Zhang et al. 2010). It meant that the quantity of AOB was not affected by COD/TP ratio under the same influent $\mathrm{NH}_{4}{ }^{+}-\mathrm{N}$ concentration and aeration stage conditions. Similar results were obtained regarding the quantity of denitrifier community. The ratios of $n o s Z /$ bacterial $16 \mathrm{~S}$ rRNA gene were $2.8 \times 10^{-5}, 1.7 \times 10^{-5}$, and $2.3 \times 10^{-5}$ in the three SBRs, which was attributed to degrade $\mathrm{NO}_{3}{ }^{-}-\mathrm{N} / \mathrm{NO}_{2}{ }^{-}-\mathrm{N}$ in liquid by existing nitrate reductase and nitrite reductase, or even the difference of gene expression ratio. The percentages of $\mathrm{AOB}$ as well as denitrifiers were quite small in all SBRs. Meanwhile, the copy numbers of amoA were about 2 4 times more than that of nos $Z$, probably due to the enough influent $\mathrm{NH}_{4}{ }^{+}-\mathrm{N}$ content and small sludge flocs. The results were different to the previous. Geets et al. (2007) investigated the microbial community structure of the WWTPs and the copy numbers of nos $Z$ were much higher than the results presented in this study. In the low DO condition, the denitrification process was partly inhibited, resulting 
in the low growth rate of denitrifiers. This may also be the reason for $\mathrm{NO}_{3}{ }^{-}-\mathrm{N}$ accumulation in the effluent.

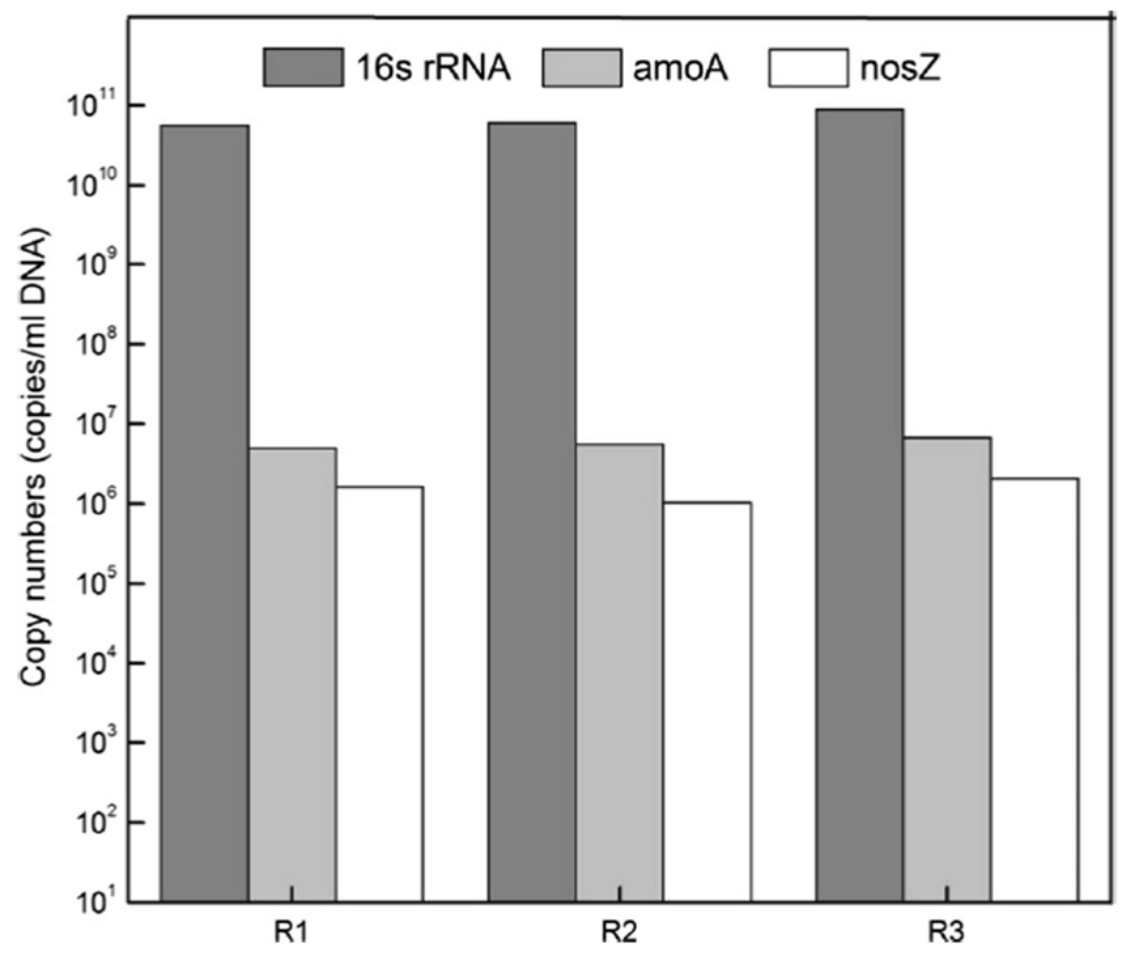

Fig. 5 Copy numbers of $16 \mathrm{~s}$ rRNA, amo $A$ and nos $Z$ genes under different COD/TP ratios (Mean value, $n=3$ )

\section{Effect of COD/TP ratio on PAOs/GAOs ratio}

The PAOs and GAOs contents in three SBRs were determined by FISH, and the results are shown in Fig. 6. It can be seen that most microorganisms were gathered in the zooglea, which was helpful to the removal of nutrients. Estimated by using Image-Pro Plus 6.0, the results of FISH showed that based on the total bacteria, the PAOs accounted for 31.88, 31.67, and $26.95 \%$ in R1, R2, and R3, respectively, while the corresponding percentages of GAOs were $34.69,32.78$, and $39.81 \%$, respectively. The results observed in this study were higher than that reported in previous literatures. Puig et al. (2007) studied the microbial community in a SBR by FISH and found that percentages of PAOs and GAOs were only 17.5 and $3.5 \%$, respectively. It showed that the PAOs were greatly enriched during the SND process in this study. Although R1 and R2 had almost the same PAOs/GAOs ratio (i.e., around 1.05), R3 presented a much higher PAOs/GAOs ratio of 1.47, which apparently increased with the decrease of influent COD/TP ratio. The results consisted with the previous studies. Mino et al. (1998) found that a low COD/P ratio in influent tends to favor the growth of PAOs instead 
of GAOs. The existence of more PAOs indicated that more microorganisms could take up phosphorus and use nitrate and/or nitrite as electron acceptor at the same time during aeration stage in R3. This appeared to be a reasonable microbiological explanation for the better TN and TP removal performance of $\mathrm{R} 3$.

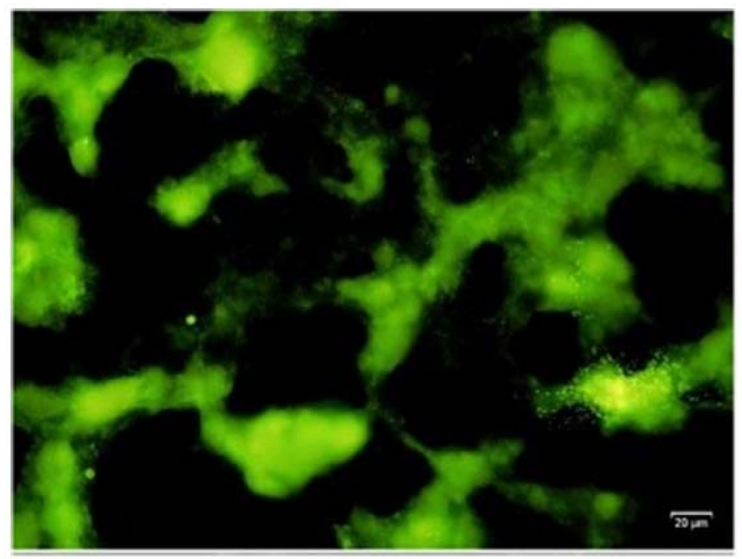

A

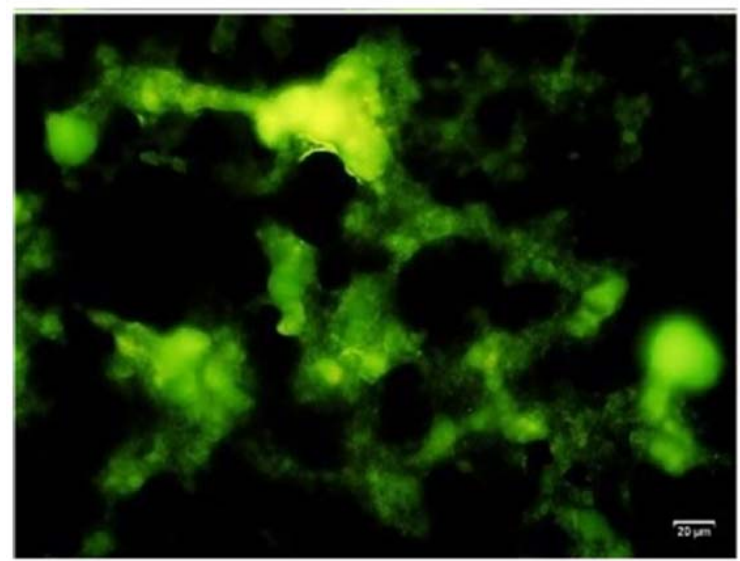

C

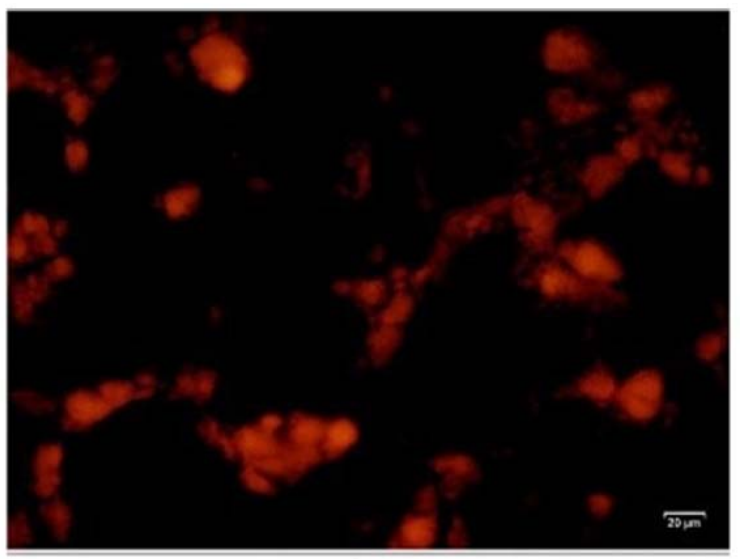

B

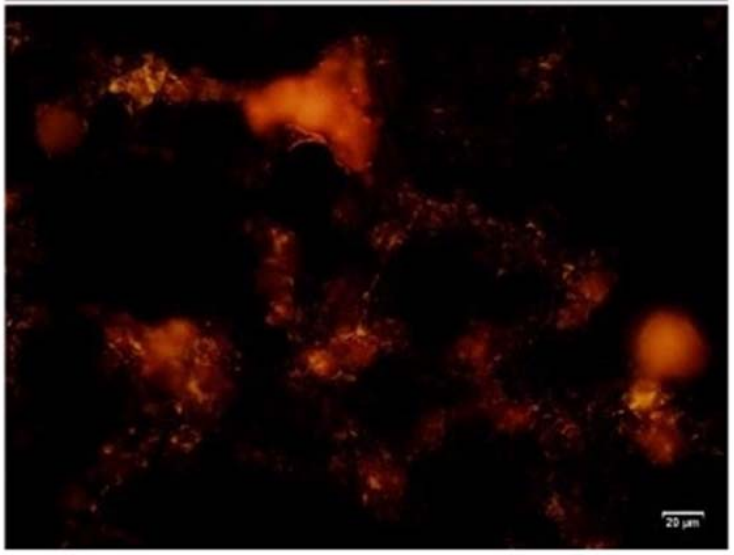

D

Fig. 6 Detection of PAOs and GAOs by FISH analysis (a and c: FITC labeled, target for Eubacteria; b: Cy3 labeled GAOmix, target for GAO; d: Cy3 labeled PAOmix target for $\mathrm{PAO})$

\section{Conclusions}

With the increase of the COD/TP ratio, the population of $\gamma$-Proteobacteria in the reactors exhibited a slightly decreasing trend. The composition of AOB community was found to be affected by the COD/TP ratio.Nitrosomonas capable of both nitrification and denitrification under low oxygen conditions was found to be the dominant AOB in all SBRs. The copy 
numbers of amoA in all SBRs were more than that of nosZ. The PAOs/GAOs ratio showed an upward trend with the decrease of influent COD/TP ratio.

\section{Acknowledgments}

This work was supported by the National Natural Science Foundation of China (No. 21177075 and 50908133), Program for New Century Excellent Talents in University (NCET10-0554), Natural Science Foundation for Distinguished Young Scholars of Shandong province (JQ201216), and Natural Science Foundation of Jiangsu Normal University (No. 13XLR023).

\section{References}

Castro Daniel LM, Pozzi E, Foresti E, Chinalia FA (2009) Removal of ammonium via simultaneous nitrification-denitrification nitrite shortcut in a single packed-bed batch reactor. Bioresour Technol 100:1100 - 1107

Chiu Y, Lee L, Chang C, Chao AC (2007) Control of carbon and ammonium ratio for simultaneous nitrification and denitrification in a sequencing batch bioreactor. Int Biodeterior Biodegrad 59:1 - 7

Chuang S, ChangW, Huang Y, Tseng C, Tai C (2011) Effects of different carbon supplements on phosphorus removal in low $\mathrm{C} / \mathrm{P}$ ratio industrial wastewater. Bioresour Technol 102:5461 - 5465

Dell EA, Bowman D, Rufty T, Shi W (2010) The community composition of soil-denitrifying bacteria from a turfgrass environment. Res Microbiol 161:315 - 325

Dupas R, Delmas M, Dorioz J-M, Garnier J, Moatar F, Gascuel-Odoux C (2015) Assessing the impact of agricultural pressures on $\mathrm{N}$ and $\mathrm{P}$ loads and eutrophication risk. Ecol Indic $48: 396-407$

Enwall K, Philippot L, Hallin S (2005) Activity and composition of the denitrifying bacterial community respond differently to long-term fertilization. Appl Environ Microbiol $71: 8335-8343$ 
Fischer-Romero C, Tindall BJ, Juttner F (1996) Tolumonas auensis gen nov, sp nov, a toluene-producing bacterium from anoxic sediments of a freshwater lake. Int J Syst Bacteriol 46:183 - 188

Fu Z, Yang F, An Y, Xue Y (2009) Simultaneous nitrification and denitrification coupled with phosphorus removal in an modified anoxic/oxic-membrane bioreactor (A/O-MBR). Biochem Eng J 43:191 - 196

Gabarro J, Hernandez-del Amo E, Gich F, Ruscalleda M, Balaguer MD, Colprim J (2013) Nitrous oxide reduction genetic potential from the microbial community of an intermittently aerated partial nitritation SBR treating mature landfill leachate. Water Res $47: 7066-7077$

Gao J, Luo X, Wu G, Li T, Peng Y (2013) Quantitative analyses of the composition and abundance of ammonia-oxidizing archaea and ammonia-oxidizing bacteria in eight fullscale biological wastewater treatment plants. Bioresour Technol 138:285 - 296

Ge S, Peng Y, Wang S, Guo J, Ma B, Zhang L, Cao X (2010) Enhanced nutrient removal in a modified step feed process treating municipal wastewater with different inflow distribution ratios and nutrient ratios. Bioresour Technol 101:9012 - 9019

Geets J, de Cooman M, Wittebolle L, Heylen K, Vanparys B, De Vos P, Verstraete W, Boon N (2007) Real-time PCR assay for the simultaneous quantification of nitrifying and denitrifying bacteria in activated sludge. Appl Microbiol Biotechnol 75:211 - 221

Hocaoglu SM, Insel G, Cokgor EU, Orhon D (2011) Effect of low dissolved oxygen on simultaneous nitrification and denitrification in a membrane bioreactor treating black water. Bioresour Technol 102: 4333 - 4340

Holman JB, Wareham DG (2005) COD, ammonia and dissolved oxygen time profiles in the simultaneous nitrification/denitrification process. Biochem Eng J 22:125 - 133

Hu Z, Zhang J, Xie H, Li S, Zhang T, Wang J (2011) Identifying sources of nitrous oxide emission in anoxic/aerobic sequencing batch reactors (A/O SBRs) acclimated in different aeration rates. Enzyme Microb Technol 49:237 - 245

Ibekwe AM, Grieve CM, Lyon SR (2003) Characterization of microbial communities and composition in constructed dairy wetland wastewater effluent. Appl Environ Microbiol $69: 5060-5069$ 
Jia W, Liang S, Huu Hao N, Guo W, Zhang J, Wang R, Zou Y (2013a) Effect of phosphorus load on nutrients removal and $\mathrm{N} 2 \mathrm{O}$ emission during low-oxygen simultaneous nitrification and denitrification process. Bioresour Technol 141:123 - 130

JiaW, Liang S, Zhang J, Ngo HH, GuoW, Yan Y, Zou Y (2013b) Nitrous oxide emission in low-oxygen simultaneous nitrification and denitrification process: sources and mechanisms. Bioresour Technol 136:444 - 451

Liu Y, Zheng Y, Shen J, Zhang L, He J (2010) Effects of mercury on the activity and community composition of soil ammonia oxidizers. Environ Sci Pollut Res Int $17: 1237-1244$

Meyer RL, Zeng RJX, Giugliano V, Blackall LL (2005) Challenges for simultaneous nitrification, denitrification, and phosphorus removal in microbial aggregates: mass transfer limitation and nitrous oxide production. Fems Microbiol Ecol 52:329 - 338

Mino T, van Loosdrecht MCM, Heijnen JJ (1998) Microbiology and biochemistry of the enhanced biological phosphate removal process. Water Res 32:3193 - 3207

Puig S, Corominas L, BalaguerMD, Colprim J (2007) Biological nutrient removal by applying SBR technology in small wastewater treatment plants: carbon source and C/N/P ratio effects.Water Sci Technol 55:135 - 141

Shrestha NK, Hadano S, Kamachi T, Okura I (2002) Dinitrogen production from ammonia by Nitrosomonas europaea. Appl Catal A Gen 237:33 - 39

Thomas M,Wright P, Blackall L, Urbain V, Keller J (2003) Optimisation of Noosa BNR plant to improve performance and reduce operating costs. Water Sci Technol 47:141 148

van Trappen S, Mergaert J, Swings J (2003) Flavobacterium gelidilacus sp nov., isolated from microbial mats in Antarctic lakes. Int J Syst Evol Microbiol 53:1241 - 1245

Wang Y, Peng Y, Stephenson T (2009) Effect of influent nutrient ratios and hydraulic retention time (HRT) on simultaneous phosphorus and nitrogen removal in a two-sludge sequencing batch reactor process. Bioresour Technol 100:3506 - 3512 
Wang Y, Geng J, Ren Z, HeW, Xing M,Wu M, Chen S (2011) Effect of anaerobic reaction time on denitrifying phosphorus removal and $\mathrm{N}_{2} \mathrm{O}$ production. Bioresour Technol $102: 5674-5684$

Yu T, Li D, Qi R, Li S, Xu S, Yang M (2011) Structure and dynamics of nitrifier populations in a full-scale submerged membrane bioreactor during start-up. Appl Microbiol Biotechnol 90:369 - 376

Zeng RJ, Lemaire R, Yuan Z, Keller J (2003) Simultaneous nitrification, denitrification, and phosphorus removal in a lab-scale sequencing batch reactor. Biotechnol Bioeng $84: 170-178$

Zhang B, Sun B, Ji M, Liu H, Liu X (2010) Quantification and comparison of ammoniaoxidizing bacterial communities in MBRs treating various types of wastewater. Bioresour Technol 101:3054 - 3059

Zhang J, Zeng G, Chen Y, Yu M, Yu Z, Li H, Yu Y, Huang H (2011) Effects of physicochemical parameters on the bacterial and fungal communities during agricultural waste composting. Bioresour Technol 102:2950 - 2956

Zhang L, Wei C, Zhang K, Zhang C, Fang Q, Li S (2009) Effects of temperature on simultaneous nitrification and denitrification via nitrite in a sequencing batch biofilm reactor. Bioprocess Biosyst Eng 32:175 - 182

Zhao C, Peng Y, Wang S, Takigawa A (2008) Effects of influent C/N ratio, C/P ratio and volumetric exchange ratio on biological phosphorus removal in UniFed SBR process. J Chem Technol Biotechnol 83:1587 - 1595 